\begin{tabular}{|c|c|c|}
\hline 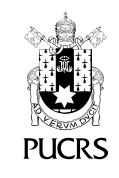 & $\begin{array}{l}\text { ESCOLA DE } \\
\text { HUMANIDADES }\end{array}$ & $\begin{array}{l}\text { Revista Digital do Programa de Pós-Graduação em Letras da PUCRS } \\
\text { Letrônica, Porto Alegre, v. 13, n. 1, p. 1-11, jan.-mar. } 2020 \\
\text { e-ISSN: } 1984-4301\end{array}$ \\
\hline de) $\mathrm{http}: / / \mathrm{dx}$ & $\mathrm{rg} / 10.15448 / 1984-4301.2020 .1 .35053$ & \\
\hline
\end{tabular}

\title{
As rotas do desejo de Zulé: faces da sexualidade em Del rojo de su sombra, de Mayra Montero
}

The routes of Zulésdesire: faces of sexuality in The red of his shadow, of Mayra Montero

\section{Renato Kerly Marques \\ Silva ${ }^{1}$ \\ orcid.org/0000-0003-2250-929X \\ renatokerly@yahoo.com.br}

Recebido em: 30 jul. 2019. Aprovado em: 16 dez 2019 Publicado em: 7 abr. 2020

\section{(c) (i)}

Artigo está licenciado sob forma de uma licença Creative Commons Atribuição 4.0 Internacional.
Resumo: Como cita Esquelin (2010), o romance Del rojo de su sombra, da escritora cubana/porto-riquenha Mayra Montero, narra diversos deslocamento realizados por imigrantes haitianos que trabalham na República Dominicana. Além dos fatores políticos e econômicos que orientam o processo migratório para a região canavieira de La Romana, o romance de Montero nos apresenta as tensões sociais e as manifestações religiosas vividas pelos haitianos. No centro da narrativa, encontramos a personagem ZuléRevé, sacerdotisa vudu que nos leva pelos caminhos da experiência mística do vuduismo e pelos caminhos da sexualidade. A partir da ideia de Butler (2003) de que sexo, gênero, desejo e prática sexual são categorias que apresentam diversas possibilidades de performance, o presente artigo analisa as experiências sexuais de Zulé como deslocamentos que borram a perspectiva de uma heterossexualidade compulsória e revisam o papel de uma familia nuclear organizada com fins de procriação.

Palavras-chave: Gênero. Desejo. Deslocamentos. Heterossexualidade compulsória.

Abstract: As mentioned by Esquelin (2010), the novel The red of his shadow by the Cuban / Puerto Rican writer Mayra Montero, narrates various displacements by Haitian immigrants working in the Dominican Republic. In addition to the political and economic factors behind the migratory wave to the sugarcane region of La Romana, Montero's novel shows us the social tensions and religious practices experienced by these Haitians immigrants. The character ZuléRevé, a voodoo priestess who leads us along the paths of the mystical experience of voodooism and the paths of sexuality is the protagonist of the narrative. Based on Butler's (2003) idea that sex, gender, desire and sexual practice are categories that present different possibilities of performance, this article analyzes the sexual experiences of Zule as displacements that erase the perspective of a compulsory heterosexuality and questions the role of a nuclear family with procreative purposes. Keywords: Gender. Desire. Displacement. Compulsory heterosexuality.

\section{Introdução}

Zulé Revé é a protagonista do Romance Del rojo de su sombra, escrito por Mayra Montero e, publicado pela primeira vez em 1992. A narrativa é situada em uma região de produção de cana-de-açúcar localizada na República Dominicana, província de La Romana, próximo à fronteira com - Haiti. O evento que conduz a narração é a organização e a realização de uma peregrinação entre a Quinta-feira Santa e o Domingo de Páscoa. A peregrinação consiste no deslocamento de uma confraria religiosa denominada Gagá pelos engenhos da região de La Romana. A narrativa é organizada a partir da alternância entre capitulos que narram os quatro dias de viagem do Gagá e capítulos que, a partir de flashbacks, apresentam passagens anteriores à peregrinação. A partir desses retornos, 
podemos compreender como o passado das personagens convergem para o desfecho da história. A narração de Montero apresenta um rico relato de elementos da organização social da região, os quais envolvem relações de trabalho, racismo, religiosidade, gênero e sexualidade, esses dois últimos elementos receberão destaque nas próximas páginas.

Na narrativa apresentada em Del rojo de su sombra, a figura do Gagá tem centralidade. Resumidamente, ele consiste em um grupo de pessoas reunidas em torno de um houngán ou uma mambo (sacerdote ou sacerdotisa vudu) que realizam suas práticas religiosas e festejos. O Gagá é a forma de organização do vudu na República Dominicana praticado por haitianos que migraram para esse país. Nesse romance, os membros da confraria são imigrantes que trabalham no cultivo de cana-de-açúcar.

A tensão no texto se estabelece a partir do momento em que Zulé Revé é ameaçada de morte por Símila Bolosse, sacerdote de um outro Gagá. A ameaça ocorre em razão de Zulé não ter realizado um acordo com Símila para cooperar em ações como contrabando e tráfico que eram realizadas pelo houngán. No espaço de desenvolvimento da trama, os flashbacks explicam a origem das personagens, as relações que as envolvem e os sentimentos nutridos por elas. Como parte do exercício de escrita do texto literário, Mayra Montero nos apresenta uma etnografia ficcionalizada sobre a população dos bateyes (nome dado às vilas dos trabalhadores dos engenhos) de La Romana.

Caracterizar a narrativa em destaque como uma etnografia ficcionalizada intenta destacar o trabalho de Mayra Montero em registrar diversos elementos do grupo social que é majoritário no Gagá, haitianos que migraram para as plantações de cana-de-açúcar da República Dominicana. Neste trabalho, tenho por objetivo fazer uma releitura do romance de Montero a partir de uma perspectiva antropológica. Nesse sentido, tentarei compreender algumas caracteristicas associadas a gênero e sexualidade a partir do contexto apresentado por Montero. Entendo que os sentidos de algumas ações narradas pela escritora não podem ser mediados por um conjunto de significados que remetem a conceitos de familia ou religiosidade baseada em valores da familia nuclear ou do cristianismo europeu, tampouco podem ser analisados exclusivamente a partir da minha experiência pessoal. Baseandome na ideia de Meneses,

Todo e qualquer elemento de uma cultura é relativo aos elementos que compõem aquela cultura, só tem sentido em função do conjunto: sua validade depende do contexto em que está inserido, de sua posição em meio de outros niveis e conteúdos da cultura de que faz parte (MENESES, 1999, p. 22).

Em Del rojo de su sombra, a autora faz uso das investigações da antropóloga June Rosemberg, El Gagá: Religión y Sociedad de un Culto Dominicano (1979). A pesquisa é a fonte para a descrição dos rituais apresentados ao longo da narrativa. Além dos dados da pesquisa, Montero incorpora uma prática de respeito aos costumes que marcam o grupo social descrito. Dessa forma, ela consegue entrelaçar literatura e antropologia (ESCABÍ, 2014).

A população dos bateyes é constituida em sua maioria por imigrantes de origem haitiana que cruzavam a fronteira para trabalhar nos engenhos, em condições de trabalho análogas às da escravidão. Os baixíssimos salários pagos, além do grande esforço físico necessário para o corte da cana-de-açúcar e os periodos em que os trabalhadores não tinham atividades remuneradas, como os meses entre a plantação e a espera até a colheita da cana (el Tiempo Muerto), afastavam a população dominicana desse trabalho.

Junto aos aspectos relacionados às práticas religiosas e aos deslocamentos dos haitianos em busca de trabalho, Montero dá relevo ao racismo enfrentado pelos haitianos que cruzavam a fronteira. Apesar do passado colonial e da experiência da escravidão no Haiti e na República Dominicana, a relação entre esses povos é marcada pela inferiorização dos haitianos. Por

2 Para uma melhor compreensão sobre o Gagá, ver Cruz (2014). 
terem a pele mais escura, os haitianos eram referidos pelos dominicanos como "congos", termo depreciativo carregado de conotação que identifica os haitianos como inferiores. ${ }^{3}$

Elementos da política haitiana também são mencionados no romance. A narrativa é marcada pelo final da ditadura da família Duvalier (François Duvalier e seu filho Jean-Claude Duvalier estabeleceram uma ditadura no Haiti entre os anos de 1957 e 1986). As referências a fatos históricos situam o romance entre os anos finais da década de 1980 e o início dos anos 1990. Símila, o antagonista, era membro da milícia que dava suporte ao governo dos Duvalier, os tontonsmacoutes. Com a queda do regime e a perseguição da milicia, os tontonsmacoutes fugiram para a República Dominicana e ali estabeleceram sua atuação.

A Ilha da Española, local que hoje é ocupado por Haiti e República Dominicana, foi dividida entre França e Espanha durante o processo de colonização das Américas. A região apresenta tensões marcadas pelos processos de exploração desenvolvidos pelas metrópoles que colonizaram a ilha. No caso do Haiti, ex-colônia da França, a exploração baseada na escravização de um grande contingente populacional de origem africana produziu um cenário que culminou com a Revolução Haitiana e o estabelecimento da primeira república negra fora da África em 1804. Junto aos efeitos políticos, sociais e simbólicos desse feito, é importante registrar que as interdições que o Haiti sofreu para ter o reconhecimento de sua independência ainda refletem na sua economia e na forma como este país é visto, sobretudo pela vizinha República Dominicana. Quanto à relação entre elementos históricos e ficcionais:

Tenemos que relacionar los fragmentos históricos y narrativos para poder entender lo extraordinario dentro de los eventos aparentemente ordinarios. La tensión entre República Dominicana y Haití parece ordinaria tras doscientos años de difícil convivencia. Ambas na- ciones se ven afectadas por fronteras hostiles no sólo geográficas sino raciales, religiosas y sexuales (ESQUELÍN, 2010, p. 1).

As tensões exploradas pelo romance apresentam a sociedade dos bateyes submetida a diferentes niveis de exploração: nas relações de trabalho com a submissão dos haitianos às regras de trabalho que os dominicanos não aceitam; nas relações histórico/raciais com os haitianos sendo considerados inferiores aos dominicanos; e nas relações de opressão estabelecida pelos milicianos, decorrentes da imposição de acordos entre as milicias e as confrarias religiosas. Na descrição de Montero, o Estado é uma entidade ausente nessa sociedade. Os Gagás são a figura mais bem formada de instituição social. Dessa forma, a figura de Zulé Revé ganha centralidade por ela ser a lider (dueña) de um Gagá respeitado na região.

Como nos mostra Villegas (2001), Montero nos apresenta um romance que trata de deslocamentos: os deslocamentos realizados pelo Gagá durante a peregrinação; os deslocamentos de Zulé e seu pai, que saíram do Haiti em busca de libertação de um amarre 4 e por melhores condições de vida; o deslocamento entre o mundo dos vivos e o mundo dos mortos, que Zulé aprendeu a percorrer durante seu processo de iniciação como sacerdotisa vudu. Além desses, os deslocamentos, dos quais trato nas próximas páginas, são os realizados por Zulé quanto às expectativas de desejo e práticas sexuais vivenciadas por ela, práticas essas que parecem borrar algumas expectativas destinadas a mulheres.

\section{As normas da sexualidade}

Ao longo da história, a sexualidade humana despertou diversas reações. No Ocidente, as avaliações sobre o desejo giram entre as perspectivas de um dilema expresso a partir de uma episteme grega que pode ser resumido em duas posições: a repressão dos desejos do estoicismo ou a vivência dos prazeres do hedonismo. Esse dilema atravessou as fronteiras

\footnotetext{
3 A tensão racial apresentada no romance é concebida a partir da significação de tons de pele de haitianos e dominicanos, mas este não é o único elemento que sustenta a distinção entre os grupos. A condição de imigrantes e a diferença econômica entre Haiti e República Dominicana operam no exercício de reforço de tal distinção em que a população dominicana se vê como superior aos haitianos 4 Amarre é uma forma de trabalho realizado por sacerdotes vudus para atender aos desejos de quem contratou este trabalho. A morte de alguns membros da familia de Zulé é atribuída à realização destes trabalhos
} 
gregas para fundamentar as regras sociais ocidentais em função da influência de tais conceitos na Teologia Cristã, colaborando na determinação de quais ações conduziriam ao inferno ou ao paraíso. Com essa separação, o acesso a um desses destinos era determinado por requisitos que identificavam, dentre outras coisas, a forma como os sujeitos deveriam experienciar sua sexualidade, reprimindo-a ou não.

Michel Foucault (1988), em sua História da sexualidade, nos mostrou que uma grande parcela da sociedade ocidental do século XIX colocou como imperativo o controle da sexualidade humana, criando uma narrativa científica que definia o que seriam homens ou mulheres e regulando quais caracteristicas estavam relacionadas a cada um desses dois modelos. Influenciada pela força de discursos cristãos, essa narrativa tinha por base a ideia de um sexo biológico sustentada pela percepção de que a genitália conteria uma verdade sobre o sujeito, sua essência. A base dessa tese compreende homens e mulheres como seres constituidos em oposição. Nesse sistema, não eram consideradas as "verdades biológicas" apresentadas, por exemplo, por sujeitos como Herculine Barbin 5 (FOUCAULT, 1982), sujeito que possuía uma genitália que não poderia identificar-lhe nem como homem, nem como mulher. Herculine seria um outro de uma teoria que não aceitava mais "um outro". Nessa narrativa de análise e classificação dos sujeitos, como nos mostrou Simone de Beauvoir (1970), a mulher já era identificada como o Outro do homem, sendo, em função disso, considerada inferior a ele. Na ausência de espaço para um Outro, e frente às dificuldades de se questionar tal "verdade genital", sujeitos como Herculine foram associados ao conceito de anormal, monstro.

Junto com a definição sobre quais seriam os sujeitos possiveis (mulheres ou homens), instituições como a Igreja, a Justiça e a Medicina sustentaram discursos que regularam a sexualidade a partir do reconhecimento de uma genitália masculina ou feminina. Dessa forma, os papéis sociais foram significados a partir do estabelecimento da assimetria de poder entre homens e mulheres, sendo regulados por discursos que podem ser resumidos pelo conceito da heterossexualidade compulsória apresentado por Judith Butler (2003).

Realizando uma crítica à tese de Lévi-Strauss (1982) que definia o tabu do incesto como a regra fundante das sociedades humanas, Butler (2003), argumenta que as sociedades teriam se organizado a partir de uma norma anterior à definição do incesto, a regra da heterossexualidade compulsória. Tal regra preconiza o estabelecimento de uma continuidade entre os elementos que, hoje, identificamos como categorias distintas: sexo, gênero, desejo e prática sexual. A perspectiva estabelecida por discursos legais, médicos e religiosos prescrevia que a partir do reconhecimento de uma genitália com determinadas caracteristica identificava-se o sexo dos sujeitos (como nos lembra Butler, limitado a duas possibilidades). A determinação de um sexo indicaria quais papéis sociais eram permitidos a um sujeito. Dessa forma, um pênis direcionava o sujeito para um conjunto de significados considerados masculinos, e uma vagina orientava para significados femininos. Seguindo essa ideia, o desejo só deveria orientarse para sujeitos em polos opostos (sujeitos com vaginas deveriam desejar sujeitos que portassem um pênis); essa regra do desejo determinava as práticas sexuais autorizadas. A partir das relações reguladas pela heterossexualidade compulsória, a prática sexual teria uma finalidade: a reprodução.

A crítica à heterossexualidade compulsória surge a partir da identificação de que a relação entre sexo, gênero, desejo e prática sexual não é automática como os discursos médicos, juridicos e religiosos sustentavam. Além disso, hoje considera-se que essas categorias (sexo, gênero, desejo) não são determinadas pelo nascimento (por uma marcação biológica), elas podem ser experienciadas de diferentes formas ao longo da vida. Nesse sentido, sexo, gênero, desejo e prática sexual podem ser vividos pelos sujeitos a partir

5 Apresentada como hermafrodita nos trabalhos de Foucault, hoje, chamada de intersexo. 
de um amplo campo de possibilidades, pelos quais os sujeitos podem deslocar-se sem que a genitália limite as possibilidades de interações sexuais entre os sujeitos.

No romance Del rojo de su sombra, a sexualidade de Zulé é apresentada como algo fluido, em deslocamento por várias possibilidades de práticas sexuais. Para Zulé, o desejo não pode ser determinado por normas sociais sustentadas pela binariedade esperada pela heterossexualidade compulsória. Zulé pode ter experiências sexuais com diferentes homens ou mulheres e, na narrativa, essas relações não são positivas nem negativas, são experiências possiveis aos sujeitos.

É importante destacar que a escrita de Mayra Montero está inserida em um contexto de crítica social que vem sendo realizada por escritores porto-riquenhos:

los escritores de Puerto Rico proponen que la perversión es también una inversión defensiva de un instinto sexual modificado por las relaciones coloniales. Sugieren, además, que si la perversión es una estructura psicológica obligatoria ${ }^{6}$. también es una estructura social necesaria bajo un régimen colonial (TRIGO, 2009, p. 1279).

Dessa forma, a discussão sobre a sexualidade apresentada por Montero deve ser lida como uma crítica à sexualidade regulada por discursos instituídos a partir das antigas metrópoles, como nos mostra McClintock:

as escravas, trabalhadoras agricolas, serventes domésticas, mães, prostitutas e concubinas das vastas colônias da Europa, as mulheres colonizadas tinham de negociar não só os desequilibrios em suas relações com seus próprios homens, mas também o barroco e violento conjunto das regras e restrições hierárquicas que estruturavam suas novas relações com os homens e as mulheres do império (MCCLINTOCK, 2010, p. 21).

Tais restrições hierárquicas ainda exercem efeito tanto sobre as sociedades que foram colonizadas quanto sobre as que colonizaram, reforçando assimetrias de poder em diferentes perspectivas. Nesse cenário, ao explorar as possibilidades de expressão da sexualidade de Zulé, a obra de Montero desestabiliza um conjunto de regras impostas pelo regime colonial, o qual regulava a vida dos povos americanos a partir de referências europeias, as quais identificavam várias expressões da sexualidade como imorais, impróprias ou anormais. Dessa forma, Del rojo de su sombra questiona os limites para a vivência da sexualidade e propõe que os limites/interdições como a heterossexualidade compulsória ou a submissão da mulher não respeitam a liberdade de possibilidades de expressão do gênero ou da sexualidade. Assim, o texto literário "apresenta exemplos de subjetividades em ação de maneira a suscitar a reflexão e a emoção, fazendo-nos perceber o lado construido e não natural do gênero" (FIGUEIREDO, 2018).

\section{0 caminho de Zulé}

A narrativa de Montero apresenta Zulé Revé como um sujeito que vive sua sexualidade guiada pelos seus desejos. Sua posição social proporciona liberdade para tal, ela é a líder do Gagá, "la que más iba a mandar"7 (MONTERO, 1992, p. 61). Essa posição é determinada pelo poder espiritual atribuído a Zulé, percebido desde seu primeiro encontro com Coridón, sacerdote que a inicia nos conhecimentos do vudu. Após o encontro com Coridón, sabemos que Zulé teria uma posição que a diferenciaria das demais mulheres. A protagonista de Montero é descrita como portadora de uma "obstinación machuna" (MONTERO, 1992, p. 18), e aqui nos é informado que, para as populações dos bateyes, ser obstinada era uma característica que estava dentro de um conjunto de expectativas relacionadas aos homens.

No contexto em que Zulé está inserida, as fronteiras entre os gêneros podem ser percebidas logo nas primeiras páginas, mas esses limites são borrados em função do destaque da personagem na condução do Gagá: "Zulé es la dueña y jamás ninguna dueña oye consejo de los hombres que pasan por ser sus aconsejados" (MONTERO, 1992,

\footnotetext{
6 Perversão é compreendida a partir da teoria freudiana sobre a sexualidade, segundo a qual todos os individuos se constituem como sujeitos desejantes.

7 As citações do romance Del rojo de su sombra (1992) serão apresentadas em espanhol, não há tradução do romance para o português.
} 
p. 17). A posição acima dos demais membros do Gagá é prerrogativa de seus lideres. A lider deve aconselhar, ter controle da situação. Entretanto, quando o grupo se encontra prestes a enfrentar as ameaças de Símila, são os homens de maior destaque no Gagá de Zulé que decidem quais são as ações necessárias para evitar o encontro com Símila. Luc Revé, Honoré Babiole e JérémieCandé tentam orientar o grupo. Nesse momento, são os homens que determinam o destino do Gagá, e é possivel observar a posição de submissão na fala de Zulé: "- No parezco dueña - susurra tristemente Zulé -. Hoy todo el mundo decide en mi Gagá" (MONTERO, 1992, p. 55).

A percepção dessas pistas lembra a discussão apresentada por Sherry B. Ortner (2017) sobre a universalidade da subordinação feminina. Ortner observa que, mesmo em sociedades matrilineares, há momentos em que as mulheres são privadas de suas posições de poder. Na narrativa em questão, enquanto Zulé é necessária para a mediação com as divindades vudus, ela tem a liderança. Quando surge um perigo que não está relacionado à prática religiosa, os homens tomam as posições de poder, e Zulé passa a obedecer às regras determinadas por eles da mesma forma que as demais mulheres.

Próximo ao desfecho da história, quando ocorre o encontro entre Zulé e Símila, a fronteira que posiciona homens em um local superior às mulheres é demarcada. Ao se encontrarem, Zulé fala: "- Este es mi territorio - truena Zulé -. Por aquí siempre ha bajado mi Gagá... Tú te metiste por un rumbo que no era el tuyo. lapós ouvi-la Símila responde] -Aaaaaaaah, dueña cabrona, ¿y de cuándo para acá una puta le marca el rumbo a un toro macho?" (MONTERO, 1992, p. 168). Zulé quer fazer valer o direito de anterioridade. Segundo ela, o seu Gagá tem direito de seguir sua peregrinação pelos caminhos que já costumava percorrer. Porém, Símila ignora o direito da sacerdotisa. Para ele, o que vale é a vontade de um homem, "un toro macho", e, diante disso, Zulé perde todos os seus direitos. Ao escolher a palavra "puta" para se referir à mambo, Símila impõe uma superioridade que submete Zulé e todas as mulheres aos desejos dele.
Junto com a discussão sobre o gênero, a narrativa apresenta as experiências sexuais de Zulé. A forma como essas experiências são narradas sugerem que, a cada experiência vivida, Zulé completava uma etapa de um percurso de aprendizado de conhecimento e domínio do corpo para a satisfação dos seus desejos.

No romance, desejo e práticas sexuais são associados a relações de poder que podem variar de acordo com o momento da vida da personagem, ou com os sujeitos com os quais ela se relaciona. Esse caminho começa a ser traçado desde sua juventude. Assistir à relação sexual de Anacaona e Luc Revé representa a introdução de Zulé aos conhecimentos sexuais:

Zulé, mientras tanto, se quedó observando la desnudez insólita de su tía y el temblor demorado que todavia traía em los pechos.

- Yo quiero verlos - le dijo, pasando apenas sus palabras por el cedazo fértil de un mandato.

Anacaona sonrió y volvió al lecho devastado donde Luc Revé la recibió con la pasión intacta. Se quisieron varias veces entre las ruinas movedizas del camastro y ya de madrugada, cuando el capataz comenzó a dar alaridos para que los hombres salieran de los barracones, ella se levantó a preparar café. Estaba aún desnuda y Zulé permaneció a su lado, mirándole el vientre sudoroso y la llovizna lenta que le bajaba por los muslos (MONTERO, 1992, p. 42).

Zulé deseja assistir ao ato sexual de sua madrasta com seu pai. Ao dizer "Yo quiero verlos", Zulé impõe sua vontade. Querer ver é a marca associada a Zulé nos seus primeiros passos por esse caminho de conhecimento da sexualidade; ver o corpo suado de Anacaona era identificar os efeitos do sexo sobre o corpo, acessar um conjunto de saberes que produziam prazer. A vontade de Zulé ameaça romper com normas que prescrevem uma sexualidade normatizada, visto que assistir ao ato sexual dos pais toca nos limites do tabu do incesto e esses limites são, de certa forma, borrados na narrativa. Se considerarmos que assistir a um ato sexual pode ser entendido como participar dele, a iniciação sexual de Zulé ocorre com seus pais. É importante lembrar que as regras que estabelecem o tabu do incesto apresentam variações de uma sociedade para outra e também podem variar em diferentes momentos históricos 
(LÉVI-STRAUSS, 1982). No texto de Montero, não há uma pista que indique alguma proibição para que os filhos vissem os pais durante o ato sexual.

Pouco depois de completar doze anos, Zulé se muda para a casa de Coridón, sacerdote vudu que irá iniciá-la nos conhecimentos e práticas da religião. Quando Zulé vai para a casa de Papá Coridón, ela ainda é inexperiente, ainda deseja compreender como ocorrem as práticas sexuais e pede para assistir a relação de Coridón com sua esposa, María Caracoles:

Muchos años atrás, cuando llegaron a la Colonia Azote, después de haber sacado a Zulé de la Colonia Engracia, lo primero que les pidió la muchacha fue que por las noches la dejaran ver. Coridón enseguida cayó en la cuenta de lo que quería, pero María Caracoles no acababa de entender y a Zulé no le costó ningún trabajo explicárselo:

- Anacaona me deja verlo todo cuando se va a la cama con mi padre.

Comprendió al fin la esposa del dueño y contra toda predicción se echó a reír y besó a la niña en las mejillas. Aquella misma noche, no sólo le permitió a Zulé que los mirara retozar, sino que la invitó a dormir con ellos. Coridón, más empequeñecido que nunca, se durmió tarde y como atolondrado por la satisfacción terrible de haber gozado de las dos mujeres (MONTERO, 1992, p. 72).

Aqui, ver significa mais que assistir à relação sexual entre Coridón e María Caracoles, pois Zulé quer participar da relação. Nesse ponto, uma nova iniciação ocorre: a apresentação de uma relação sexual a três parece romper com a ideia de família que prevê o sexo como atividade realizada por um casal composto por um homem e uma mulher. A satisfação de Coridón por ter gozado com duas mulheres parece confirmar a posição de dominação ou supervirilidade masculina como uma distinção entre as experiências entre homens e mulheres. O caminho de Zulé passa por um território que para a sociedade europeia do século XIX e XX era reconhecido como pertencente a uma sexualidade perversa $^{8}$ (FOULCAULT, 1988). Sob a perspectiva de uma regulação sexual, as experiências da personagem com o voyerismo e o ménage à trois seriam identificadas como desvios da sexualidade, mas, no texto, não é possivel identificar algum conflito entre as ações de Zulé e um código moral.

Certamente, as determinações sobre quais práticas sexuais são aceitas ou não em uma determinada sociedade devem ser compreendidas a partir do contexto de regulação da mesma. Por exemplo, na sociedade pós Revolução Industrial, a organização das relações da familia proletária para o trabalho reduziu o sexo ao objetivo, pelo menos em teoria, exclusivo da reprodução.

É necessário contextualizar essa regulamentação das práticas sexuais, relativizando os seus efeitos em diferentes sociedades. A ideia de relativização aqui empregada quer dizer que voyerismo ou ménage à trois não têm em si sentidos negativos ou positivos, mas, da mesma forma como ao gênero são associados diferentes significados em diferentes contextos, com as práticas sexuais ocorre o mesmo processo. Desse modo, para alguns grupos sociais, certas práticas não pertencem ao leque de possibilidade de experiências permitidas. Na sociedade europeia do século XIX, as igrejas cristãs, a medicina, e mesmo o direito, afirmavam os efeitos nocivos de práticas sexuais que não priorizassem a procriação.

Para Zulé, a ampliação do conhecimento sexual está associada a sua iniciação nos conhecimentos do vudu e o acesso a esses conhecimentos delimitam a última etapa de sua iniciação para a vida social:

\footnotetext{
Una semana más tarde, Zulé volvió a repetirle que ella queria mirar. Coridón, que también esta vez sabía de lo que se trataba, disimuló como pudo:

- Ya nos estás viendo bastante.

Pero ella insistió. No era de los retozos de lo que le hablaba. Quería ver de lo otro. De lo que contaban los hounganes más viejos que les daba grima; de lo que no se podía ni adivinar con los ojos de este mundo: queria ver el paisaje natural de todos los difuntos (MONTERO, 1992, p. 72).
}

Novamente, Zulé "queria ver", mas seu desejo agora extrapolava o interesse sexual. Ela quer conhecer o mundo dos mortos, quer ter acesso ao conhecimento que era dominado apenas

8 Tal conceito diz respeito a uma ruptura entre práticas sociais/sexuais, por exemplo, o sexo com fins de reprodução da espécie seria a prática aceita, enquanto práticas como o voyerismo, ou outras que não tivessem como finalidade a reprodução, seriam consideradas como perversões, desvios de um código moral estabelecido (FOUCAULT, 1988). 
pelos sacerdotes mais velhos. Depois que ela aprende a caminhar pelo mundo dos vivos e dos mortos, sentindo com seu corpo os efeitos desse aprendizado, a postura de Zulé muda. A partir desse momento, não é mais ela quem quer ver; ela é aquela que conhece, e o acesso de outras pessoas a esse conhecimento será negociado. JérémieCandé, filho de PapáCoridón, deseja ter acesso a tal saber; ele quer fazer sexo com ela e quer vê-la fazendo sexo com seu pai ou com um outro parceiro. Agora é a sacerdotisa quem vai decidir quando, como e com quem ela fará sexo, ou quando e como Jérémie poderá participar ou assistir às relações sexuais.

Na narrativa, apósessa fase de iniciação, Zulé adquire um status de mestra, Jérémie "Ahora sólo obedece a Zulé" (MONTERO, 1992, p. 48). Como mestra, Zulé conduz Jérémie pelos caminhos da sexualidade:

Anacaona despertó de madrugada, avisada por unos ruidos que le recordaron el trasiego febril de las mangostas. Temiendo que hubieran vuelto, se levantó con sigilo, buscó con qué alumbrarse y salió de la casa sin hacer ruido para no despertar a Papá Luc. Alli, junto al corral vacio que ahora servía de basurero, los encontró ya inmóviles: tumbado boca arriba, Jérémie Candé; sudorosa, erguida, sentada sobre el otro cual reina em su verdadero trono estaba Zulé. Ninguno de los dos la sintió llegar y fue ella misma quien se decidió a cortar la noche con su voz de pájaro (MONTERO, 1992, p. 61).

Ao fazer sexo com Jérémie, Zulé não é mais alguém que deseja ver/aprender. Ela domina, tem controle sobre a situação, o que fica evidente na forma como a narradora a descreve como "uma rainha em seu trono". Assim, não parece haver limites para o desejo de Zulé. Jérémie é filho de Coridón, amante/marido de Zulé; novamente, as fronteiras do incesto são borradas, já que, pela relação de parentesco, Zulé é madrasta de Jérémie. Nesse caso, Anacaona é quem lembra que há limites que deveriam ser obedecidos: a sacerdotisa não deveria fazer sexo com o filho de seu marido. Mas esse impedimento pode mudar em um determinado contexto. Prestes a morrer, Coridón orienta que, após a morte dele, Zulé se case com Jérémie, mas ela desobedece a essa orientação.
O caminho percorrido pela personagem apresenta um ponto de rompimento entre a prática sexual e a produção de filhos. O corpo de Zulé só será usado para o prazer, o caminho seguido pela personagem rompe com a aparente relação entre mulheres e maternidade. Após um periodo em que ela tem relações sexuais com Coridón e com o filho deste, Jérémie, Zulé fica grávida. Junto com Anacaona, as mulheres ficam preocupadas com a possibilidade de a criança não se parecer com Coridón (Jérémie é filho de Coridón com uma mulher chinesa, portanto, apresenta traços que o distingue da população dos bateyes). Se isso acontecesse, Coridón descobriria a traição de Zulé e de Jérémie 9 . O bebê nasceu e não despertou nenhuma dúvida sobre a paternidade, mas a criança morreu poucos dias após o nascimento. Zulé, então, decidiu que não teria mais filhos.

$$
\begin{aligned}
& \text { El primer nieto de Papá Luc nació un Miércoles } \\
& \text { de Ceniza, cuando ya en el Gagá de su pa- } \\
& \text { dre se organizaban los festejos de la Semana } \\
& \text { Santa. Anacaona viajó desde el batey Colonia } \\
& \text { Engracia para conocer al niño y le llevó de re- } \\
& \text { galo un ropón de yute que le trabajó su proprio } \\
& \text { abuelo, con tabaco y aguarrás, para espantar } \\
& \text { el mal de ojo. [...] } \\
& \text { El niño recibió el nombre de Florvil Coridón, } \\
& \text { pero no alcanzó a llevarlo mucho tiempo [...] en } \\
& \text { la madrugada del Domingo de Resurrección } \\
& \text { la criatura dejó de respirar. l...] } \\
& \text { - Ni uno más - gritó. } \\
& \text { Y cumplió su promesa. Desde entonces, se vio } \\
& \text { en la necesidad no sólo de rechazar de vez en } \\
& \text { cuando a su marido, sino también de abandonar } \\
& \text { del todo a Jérémie Candé (MONTERO, 1992, p. 62). }
\end{aligned}
$$

A decisão de não ter mais filhos faz com que Zulé limite as suas relações sexuais. Ela evita as investidas de Jérémie e retarda os encontros com Coridón. Após a morte do marido, ela passa um longo período até encontrar um novo parceiro sexual. O desejo de Zulé continua a orientá-la pelos caminhos da sexualidade. Quando ela conhece Símila Bolosse uma nova experiência se apresenta.

Símila era um tontommacoutes, membro da milicia que dava suporte ao governo da Familia Duvalier. Com a queda deste governo, os 9 É importante lembrar que a gravidez de Zulé e o medo de que Coridón descobrisse a traição faz com que lembremos que a monoga-
mia, como norma social, é uma regra presente na sociedade dos bateyes e serve para a organização das familias. 
macoutes foram perseguidos pelo novo governo, o que levou muitos deles a cruzarem a fronteira e buscarem abrigo na República Dominicana. É após essa fuga que Símila encontra com Zulé. Ele procurava abrigo e tratamento para os ferimentos que sofrera durante a fuga do Haiti.

O encontro entre Zulé e Símila apresenta uma prática sexual em que as personagens são animalizadas. Zulé, que havia dominado as relações com seus últimos parceiros, tem uma experiência em que ela é dominada:

[...] Similá Bolosse pidió manteca de majá para curarse las desolladuras y Zulé se ofreció para untársela. Ella misma lo acabó de desnudar, arrancándole aquel taparrabo percudido que alguna vez fue pantalón, y luego comenzó a frotarle el cuero encendido, mientras el hombre gemía porque le avivaba los aguijonazos del monte. Cuando hubo terminado con la manteca de majá, trajo la pócima de palo para ablandarle las postillas del pecho.

- Aquí también - ordenó Similá llevándole la mano hasta su bajo vientre.

Ella obedeció, contenta de recibir mandatos después de tantos años em que sólo había podido darlos.

- iY aqui!

Nunca supo Zulé si el hombre de Paredón había dicho aquellas palabras o era ella quien las había adivinado, mirándolo a los ojos, hundiéndose en los círculos soleados de esa visión proscrita. Lo próximo que escuchó fue el golpe de su propio cuerpo que cayó redondo sobre el piso de tierra, inútil y pataleante como un carey puesto sobre su concha. Simila Bolosse la destazó así mismo, como se destazaban los careyes de la costa, la revolcó sobre los taburetes derribados y la sometió mil veces, haciéndola besar la tierra (MONTERO, 1992, p. 91).

A violência dessa relação apresenta uma nova possibilidade de expressão do desejo de Zulé. Ela é dominada por Símila, "receber ordens depois de tantos anos em que ela só havia ordenado deixou-a alegre". Apesar da cena se aproximar da descrição de um estupro, parece que a personagem deseja ser dominada. Não fica claro quem deu início à relação. Zulé não tem noção se foi Símila que falou, ou ela que quis ouvi-lo ordenar que aproximasse a mão do pênis dele. Depois de ser a dominadora na relação com Jérémie, a sacerdotisa era dominada. Assim, ocorria mais uma fase do seu aprendizado. Após esse primeiro encontro, Zulé se apaixona por Símila. Ao longo da narrativa, ela tentará reencontrá- lo. A ponto de, em determinado momento, aceitar a tarefa de resgatar uma mulher que estava vivendo próximo ao Lago Péligre. Essa viagem ganha ares de um estratagema para encontrar Símila, que morava às margens desse lago.

Frente ao desejo de Zulé, a personagem Anacaona funciona como um elemento repressor. É ela que nos apresenta quais seriam os comportamentos esperados para uma mulher dominicana. ÉAnacaona quem tenta reestabelecer a norma, lembrar a Zulé o que é permitido e o que é proibido, é ela quem percebe quando Zulé iniciou sua vida sexual: "Zulé no se tomó el trabajo de fingir, pero Anacaona se loaclaró de todos modos. - Se te nota que ahora sí probastela candela" (MONTERO, 1992, p. 47). Éa tia/ madrasta que alerta a sacerdotisa para o "erro" do envolvimento com Jérémie, filho de Coridón. Após o encontro com Símila, novamente, é Anacaona quem adverte Zulé sobre o comportamento impróprio que ela teve. Após ter feito sexo com Símila, a sacerdotisa foi levar o almoço de Jérémie no canavial. Todos os sinais deixavam perceber que ela havia feito sexo com o macoute, mas, Anacaona precisava perguntar-lhe:

\footnotetext{
-Tú le untaste la manteca - le dijo Anacaona Y ese bicho malo, dueña, ¿me vas a decir qué carajos te estaba untando a ti?

Todavía andaba con los pechos desnudos, la primera vez en su vida que llevaba el almuerzo a los cortes sin echarse una batola por encima. [...]

- Además, muchacha, se te nota...

[...] Anacaona aprovechó para hundir su dedo junto al pezón morado de la dueña:

- Se nota que te las mamaron (MONTERO, 1992, p. 92)
}

Anacaona apresenta a Zulé, o que parece imperceptivel a ela. Estar untada com a manteiga que ela havia passado nas feridas de Símila, estar com os seios à mostra, o que ela não tinha o costume de fazer e, sobretudo, estar com o bico do peito marcado denunciando que ele havia sido sugado, não deixava dúvida de que ela havia feito sexo com um homem que preocupava a todos, pois ele era um macoute (membro da milicia haitiana). No Haiti, Símila era um poderoso bokor, um sacerdote vudu que trabalha com atividades que podem prejudicar alguém. Poucos anos depois de conhecer Zulé, Similá se tornou um 
importante traficante da região de La Romana e submetia todos os Gagás às suas regras. Apenas o Gagá de Zulé não colaborava com as atividades de Simila, e por isso, a mambo estava ameaçada de morte, enredada em uma trama criada pelo bokor.

Como havia dito, além da busca pela satisfação do seu desejo, Zulétem o controle do seu corpo. Após o encontró com Símila, ela engravida e não parece hesitar em cumprir a promessa de não ter mais filhos: "Zulé se desangraba [...] Anacaona que fuera a ver lo que pasaba. - Pasa lo que tenía que pasar - respondió ella tranquilamente -. Está botando a la criatura" (MONTERO, 1992, p. 106). Provocar o aborto coloca Zulé como sujeito no comando de sua atividade reprodutiva. Para Anacaona, o aborto temum significado importante, pois ele representa a eliminação da presença de Simila no batey e,talvez, a liberação de Zulé da paixão que ela nutria por ele.

A última trilha do desejo percorrido por Zulé é realizada na companhia de ChristianáDubois, Rainha da Guerra do seu Gagá..$^{10} \mathrm{O}$ encontro das duas ocorre na véspera do novo encontro com Símila, momento em que Zulé vai morrer:

La muchacha, todavia aterida, se enrosca alrededor del cuerpo de la hija de Papá Luc, que le besa suavemente el rostro y le pide que se duerma. [...] La dueña la besa más fuerte: que se duerma ahora, mañana es un gran día y comerán puerco asado en Boca Chica. Christianá deja de preguntar y empieza ella también a lamer los labios de la que más ordena. El barracón huele a tabaco y a calor de vientre; huele al regüeldo de los picadores y huele, sobre todo, al aguardiente largo que se bebió la dueña. El cantor guarda silencio unos instantes, como si estuviera tomándole el pulso a la noche. Zulé trata de no hacer ruido, pero los dulces pechos de aquella reina suya coletean y saltan dentro de su boca como pescaditos de orilla (MONTERO, 1992, p. 139).

Jérémie Candé se aventura hasta el lugar del barracón donde se apiñan las mujeres del Gagá y sacude a la hija de Papá Luc, que duerme abrazada al cuerpo casi azul de su Reina de Guerra (MONTERO, 1992, p. 149).

Cada experiência sexual apresentada pela narradora é carregada de novas possibilidades. Desta vez, não parece haver uma dominadora ou uma dominada, dado que as relações de poder se equilibram e as duas mulheres parecem em posição de igualdade. Os beijos, a língua passando pela cara, os peitos saltando para a boca de Zulé são a experiência que faltavam para a mambo. No conjunto das relações simbólicas que regem o Gagá, essa relação funciona como uma transferência de poderes (ESQUELÍN, 2010, p. 8), já que Christianá será a nova lider do Gagá. Em poucos instantes, Zulé, montada por Erzulie Freda, será morta por Jérémie, por sua vez montado por Papá Carfu.

Como observa Esquelín (2010, p. 3) "la novela enfatiza la perspectiva femenina frente al sexo, los aspectos sociales aceptables e inaceptables para una mujer y la forma de cuestionarlos y socavarlos". Nesse sentido, as tensões que existem entre Anacaona e Zuléexpressamesses limites, mas eles são reorganizados pela mambo que considera o desejo como imperativo que deve ser posto acima das convenções sociais. Naviagem realizada por Zulé, o sexo entre mulheres é a expressão de um amor que conforta e acalma. A forma com que Zulé dorme abraçada a Christianá lembra o processo de iniciação de sacerdotisa: "Durmieron como siempre, los tres en el mismo lecho, y despertaron como todos los dias: Coridón enroscado al cuerpo imposible de Zulé y Maria Caracoles abrazándolos a ambos" (MONTERO, 1992, p. 74). O conforto desseencontro com Christianá establece um ponto de contato com o início da trilha seguida por Zulé, o retorno a esse ponto de início, marcado pelo abraço de Coridón e Maria Caracoles, prepara os momentos finais da personagem.

\section{Considerações finais}

A análise proposta do romance Del rojo de su sombra identifica as experiências sexuais vividas por ZuléRevé como experiências de aprendizado. Viver diferentes possibilidades de expressão da sexualidade se apresenta como uma forma da protagonista ter acesso a um conjunto de conhecimentos sobre seus desejos e sobre seu corpo. A marca da personagem de Montero pode ser resumida na busca por um saber, sintetizado em seu interesse por ver os atos sexuais das pessoas com quem ela convivia e para ver o mundo espiritual

10 Se pudéssemos comparar o Gagá com a Umbanda, Christianá tem função semelhante a uma filha de santo. 
que ela poderia acessar como sacerdotisa vudu.

A construção da personagem Zulé está intimamente associada à simbologia da lo ${ }^{11}$ que a acompanha, Erzulie Freda. Para os praticantes do Vudu, Erzulie Freda representa o "espírito" de amor, beleza e luxo. Como elemento importante para entender as associações simbólicas propostas pelo romance, é importante destacar que "en el panteón vudú, los loas cambian de género sin problema y de acuerdo con la necesidad del momento" (ESQUELÍN, 2010, p. 8).

Essa possibilidade de viver as diferentes experiências de gênero sugerem que é a partir da associação de Erzulie Freda com Zulé Revé que Montero tece a narrativa que apresenta uma experiência de sexualidade que borra a matriz da heterossexualidade compulsória. A narradora apresenta um variado repertório de experiências sexuais possiveis a mulheres, apresentando também uma experiência de gênero em que a mulher tem controle do seu corpo tanto para a prática sexual quanto para decidir sobre a continuidade ou não de uma gravidez.

O romance de Mayra Montero é uma forma de questionar os significados associados às experiências sexuais e de gênero, identificando tais experiências como relacionadas a contextos históricos e sociais, que no caso do romance em destaque, problematizam concepções que regulam as experiências sexuais de muitos sujeitos.

\section{Referências}

BEAUVOIR, Simone. O segundo sexo. 1. Fatos e mitos. São Paulo: Difusão Europeia do Livro, 1970.

BUTLER, Judith. Problemas de gênero: feminismo e subversão da identidade. Rio de Janeiro: Civilização Brasileira, 2003.

CRUZ, Alline Torres Dias da Cruz. Sobre dons, pessoas, espiritos e suas moradas. $236 \mathrm{fls}$. Tese (Doutorado em Antropologia Social) - Universidade Federal do Rio de Janeiro, Rio de Janeiro, 2014. https://doi. org/10.5753/ersirj.2018.4649

ESCABÍ, Maria Isabel Chaparro de. Realidad y Ficción en las Novelas de Mayra Montero: un acercamiento desde el nuevo periodismo. 478fls. Tese (Doctorado em Teoría de la Literatura y Literatura Comparada) Universidad de Valladolid, Valladolid, 2014. https:// doi.org/10.35376/10324/4905
ESQUELINN, Mary Ann Gossier. Del rojo de su sombra de Mayra Montero: cruzando fronteras. In: Letras Hispanas: Revista de Literatura y de Cultura, v. 7, n. 1, p. 1-10, 2010.

FIGUEIREDO, Eurídice. Desfazendo o gênero: a teoria queer de Judith Butler. In: Criação \& Crítica, n.20, p.40-55, 2018. https://doi.org/10.11606/issn.19841124.voizop40-55

FOUCAULT, Michel. História da sexualidade I: a vontade de saber. Rio de Janeiro, Edições Graal, 1988.

FOUCAULT, Michel. HerculineBarbin: o diário de um hermafrodita. Rio de Janeiro: Francisco Alves, 1982.

LÉVI-STRAUSS. Claude. As estruturas elementares do parentesco. Petrópolis: Vozes, 1982.

MCCLINTOCK, Anne. Couro Imperial: raça, gênero e sexualidade no embate colonial. Campinas: Editora da Unicamp, 2010. https://doi.org/10.1590/s010483332013000100014

MENESES, Paulo. Etnocentrismo e relativismo cultural: algumas reflexões. In: Revista SymposiuM, ano 3. p. 19-25, 1999

MONTERO, Mayra. Del rojo de su sombra. Barcelona: Tusquets Editores, 1992.

ORTNER, Sherry B. Está a mulher para o homem assim como a natureza para a cultura? In: Traduções da Cultura: Perspectivas Criticas Feministas (1970-2010). Florianópolis: EDUFAL; Editora da UFSC, 2017.

TRIGO, Benigno. Vicisitudes de lo perverso en la literatura de Puerto Rico: desde El Puertorriqueño Dócil hasta El Capitán de los Dormidos. In: Revista Iberoamericana. v. 75, n. 229, p. 1253-1282, 2009. https://doi. org/10.5195/reviberoamer.2009.6634

VILLEGAS, Carmen M. Rivera. Nuevas rutas hacia Haiti en la cartografía de Mayra Montero. In: Revista Hispánica Moderna, ano 54, n. 1, p. 154-165, 2001.

\section{Endereço para correspondência}

Renato Kerly Marques Silva

Universidade Federal de Santa Catarina - Campus Trindade, Centro de Comunicação e Expressão

Campus Universitário Reitor João David Ferreira Lima, $\mathrm{s} / \mathrm{n}^{\circ}$

Bloco B, Sala 329, $3^{\circ}$ andar

Trindade, 88040-900

Florianópolis, SC, Brasil.

\section{Renato Kerly Marques Silva}

Doutorando em Literatura pela Universidade Federal de Santa Catarina (UFSC, Florianópolis, SC, Brasil), professor da Secretaria Estadual de Educação do Estado do Maranhão (SEDUC-MA) em São Luís, MA, Brasil.

11 Loa é o nome que indica uma divindade do panteão Vudu 